Angerami E.L.S. e Colaboradora - De Como o Enfermeiro Está Inserido no Seu "Espaço". Rev. Bras. Enf.; RS.36: 123 - 129, 1983.

15. GONÇALVES, R. B. M. - Medicina e história: raízes sociais do trabalho médico. São Paulo, USP/F. M., 1979. Dissertação (Mestrado). Faculdade de Medicina da USP, 209 p.

16. GRUPO 107 - Sémiotique de l'espace, Paris, Publication du Groupe 107, 1973, p.29 apud BETTANINI, T. Espaço e ciências humanas. Trad. por Liliana L. Fernandes. Rio de Janeiro, Paz e Terra, 1982, 157 p.

17. GUILVAUD, M.G. Th. Espaces et mathématiques in A.A.V.V. Notes Methodologiques en architecture et urbanisme. 3/4 sémiotiques de l'espace, Paris, Institut de L'Environnement, 1974, p.285. In. BETTANINI; T. - Espaço e ciências humanas. Trad. por Liliana L. Fernandes. Rio de Janeiro, Paz e Terra, 1982, 157 p.

18. NOGUEIKA, R. P. - Capital e trabalho nos serviços de saúde. Rio de Janeiro, 1981 (mimeografado).

19. OGUISSO, T.; SCHMIDT, M. J. - Problemas assistenciais de enfermagem nos hospitais e clínicas particulares. Rev. Bras. Enf., 28(1): 24-34, jan/mar., 1976.

20. OLIVEIRA, M. I. R. - Funções médicas delegadas, p. 34, in: SEMINÁRIO NACIONAL sobre currículo do Curso de Graduação em Enfermagem. São Paulo, nov. 25-30, 1968. São Paulo, USP/Escola de Enfermagem O. P. A. S., 1969.

21. OLIVEIRA, M. I. R. - Relaçōes da enfermagem com as demais carreiras universitárias. In: CONGRESSO BRASILEIRO DE ENFERMAGEM, 29, Camboriú, 1977. Anais, Camboriú, ABEn, 1977 p. 59-63.

22. PICANÇO, I. T. et alii - Uma tentativa de avaliaçào dos serviços de enfermagem de hospitais contratados pelo Instituto Nacional de Previdência Social I. N. P. S. em São Paulo, 1972. Rev. Bras. Enf., 25(4): 193-214, jul. set., 1972.

23. PLUCKHAN, M. L. - Professional Territoriality - A problem affecting the delevery of health care, Nursing Forum, 11(3): 300-311, 1972.

24. RIBEIRO, C. M. - Discurso de posse. In: CONGRESSO BRASILEIRO DE ENFERMAGEM, 32 , Brasília, jun. 1-7, 1980. Anais, Brasîlia, ABEn, 1980, p. 21-23.

25. SANTOS, I. - apud SEMINÁRIO NACIONAL sobre Currículo do Curso de Graduação em Enfermagem, São Paulo, nov. 25-30, 1968. São Paulo, USP/Escola de Enfermagem/O. P. A. S., 1969, p. 31.

26. SILVA, A. X. - Enfermeiro profissional: autônomo ou subsidiário? In: CONGRESSO BRASILEIRO DE ENFERMAGEM, 31, Fortaleza, ago. 5-11, 1979. 'Anais, Brasília, ABEn, 1979, 71-84 pp.

27. STEVENS, B. J. - Nursing theory: analysis, applications, evaluation. Boston, Little-Brown, $1979,280 \mathrm{p}$.

28. TREVIZAN, M. A. - Estudo das atividades dos enfermeiros-chefes de unidades de internação de um hospital-escola. Ribeirão Preto, USP/Escola de Enfermagem, 1978. Dissertação (Mestrado). Escola de Enfermagem da USP, 117 p.

29. VÁSQUEZ, A. S. - Filosofia da praxis. Trad. Luiz Fernando Cardoso, 2a ed., Rio de Janeiro, Paz e Terra, 1977, 454 p.

\title{
OS IDOSOS E A REALIDADE DA VELHICE*
}

** Daisy Leslie Steagall-Gomes

*** Tereza Cristina Scatena

$\mathrm{ReBEn} / 02$

Gomes D. L. S. e Colaboradora - Os Idosos e a realidade da Velhice ${ }^{*}$ Rev. Bras. Enf.; RS, 36: $129-151,1983$

\section{RESUMO}

Com o objetivo de conhecer o que acontece com as pessoas que envelhecem e o que elas dizem ser o envelhecimento, as autoras realizaram um trabalho de pesquisa através de entrevistas com pessoas idosas, num total de 93. Dessas, 55 eram albergadas em instituições filantrópicas para idosos e

** Professor Assistente da Escola de Enfermagem de Ribeirão Preto da Universidade de São Paulo

*** Auxiliar de Ensino da mesma Unidade (EERP - USP) 
Gomes D.L.S. e Colaboradora - Os Idosos e a realidade da Velhice ${ }^{*}$ Rev. Bras. Enf.; RS, 36: $129-151,1983$.

38 residiam na comunidade. Os resultados obtidos mostram relações da velhice com o trabalho, a família, e a saúde, evidenciando que os chamados fatores sociais influem no envelhecimento e no modo pelo qual as pessoas vivem a sua velhice.

\section{INTRODUÇÃO}

As anotações sobre a velhice são antigas e diversificądas. O Eclesiastes, livro de data incerta, mostra o pensamento judaico da época expressando que a mocidade deve preparar-se para a velhice e para a morte, assim anotando em seu capítulo 12, "Lembra-te do teu Criador nos dias de tua mocidade, antes que venham os maus dias, e cheguem os anos dos quais venhas a dizer: Não tenho n'eles contentamento" 6 .

Existem muitas outras abordagens, dentro da própria bíblia sobre o assunto, como também nos antigos livros Chineses, Indus, Romanos e nos atuais, mostrando as condições dos velhos e suas ligações com a sociedade.

O Brasil, país de jovens em fase de desenvolvimento, parece estar numa situação ainda desfavorável quanto a condição dos velhos, pois se encontra voltado para o controle das doenças transmissíveis, a desnutrição e a pobreza, com elevado índice de mortalidade infantil, insuficiente assistência médica, que constituem obstáculos para nossa longevidade, sendo pouca até agora a atenção que tem sido dispensada às pessoas idosas, cuja população, apesar de ser ainda pequena, tende a aumentar. Para uma população geral de 119.070 .865 pessoas contamos com 7.699.068 pessoas de sessenta ou mais anos. ${ }^{7}$

O atual Ministro da Saúde, Dr. Waldyr Arcoverde, criticou a discriminação do idoso na força de trabalho, na sociedade e na própria família. "O idoso é útil e sempre novo no simples fato de existir", lembrando que no decênio $70 / 80$ a população brasileira com mais de 60 anos cresceu em $62 \%$, enquanto no mesmo período, houve um incremento de apenas $28 \%$ da população do país como um todo. A vida média do brasileiro chega hoje a 65 anos. O Ministro da Saúde diz que o Brasil conta atualmente com 7,6 milhões de idosos (em 1970 não chegava a 4,8 milhões) ${ }^{1}$.

Nessa mesma matéria do jornal "O Estado de São Paulo"1, há os pronunciamentos de: Hector Acuna, diretor geral da OPS "os idosos podem dar grandes e significativas contribuições à sociedade, permanecendo produtivos muito além da idade obrigatória de aposentadoria e dando-nos o benefício de sua sabedoria e experiência. Só resta aos governos e outras organizações e grupos jovens da população, compreender o alcance da contribuição que os idosos podem dar, se lhes forem proporcionadas as oportunidades" e o do Dr. Halfdan Mahler, presidente da OMS: "acredito que muito esforço precisará para mudar uma situação praticamente instalada nos países em densenvolvimento: Os velhos estão sendo afastados das tradiçōes das próprias nações, que concedem aos idosos um lugar de honra. Os governos devem ter muito cuidado para não criarem outras situações que excluam os velhos dos trabalhos que eles querem e são capazes de desempenhar".

Outra consideração a ser feita é que as populações dos países em desenvolvimento, que têm uma estrutura jovem, envelhecerão, se sua fertilidade acompanhar a tendência decrescente, acrescentando ainda que a redução da mortalidade durante a segunda metade da vida levará a um envelhecimento maior da população.

OMS16, prevê que entre os anos de 1970 e 2000, no mundo inteiro, todas as idades deverão crescer $73 \%$, mas a população de 60 anos ou mais crescerá $91 \%$ ao passo que a de 80 anos ou mais crescerá $119 \%$, ou seja, quase uma vez e meia mais rapidamente, que a população mundial de todas as idades.

A mensagem divulgada para o Dia Mundial da Saúde pela OMS/OPS, neste ano de 1982, é o tema "Remoçar a velhice", e o compromisso maior, lembram os dirigentes das duas instituições, é dos países do Terceiro Mundo, que assumiram no plano de ação para o ano de 2000 a meta mínima de aumentar a probabiidade de vida para pelo menos 70 anos, enquanto hoje na América Latina a média de vida da população é de 63,7 anos"'1.

A velhice pode ser definida e conceituada de várias formas, como nos mostra a bibliografia a respeito, mas as observações demonstram que tanto na teoria como na prática, em resumo as bases são: idade cronológica (o tempo como índic das modificações sofridas) e aposentadoria (como se ela funcionasse como idade padrão cientificamente reconhecida).

OMS16 refere que o que se sabe é qie o envelhecimento é um processo de diferenciação, tanto do organismo quanto entre os serès humanos individuais. Segundo parece, numerosas modificações psicológicas têm relação direta com o envelhecimento mas, a despeito dessas modificações, a maioria das pessoas idosas retém suas capacidades funcionais, não obstante seu aparente declínio orgânico. $\mathrm{O}$ declínio do funcionamento intelectual tem mais relação com a doença do que o envelhecimento. 
KERVOR ${ }^{14}$, sem tentar responder o que seja velhice resume conclusões que têm aparecido ultimamente, dizendo "que o fenômeno não é puramente biológico, parece incontestável que numerosos elementos afetivos concorrem de forma direta para o processo de envelhecimento. Sentir-se isolado, inútil afastado de grupos, sem laços familiares, amistosos, sociais, sem atividade reconhecida, acelera, sem dúvida alguma, o envelhecimento.

Conservar certa atividade intelectual, criadora ou afetiva, é indispensável ao bom funcionamento do organismo. O corpo e o espírito envelhecem juntos, e um estimula o outro, pois o homem é um todo."

Pelas implicações de que se vê cercada a idade mais avançada e pelas dificuldades de se estabelecerem com clareza as relações de causa e efeito, pode-se dizer que o envelhecimento fisiológico e os problemas patológicos são difíceis de serem delineados com clareza, não havendo um marco cronológico referido como oficialmente aceito.

$\mathrm{Na}$ abordagem deste trabalho será usado como marco cronológico de referência a idade de 60 anos ou mais reconhecendo que o estabelecimento deste limite para considerar uma pessoa velha ou idosa, é uma questão de ordem estatística e metodológica do trabalho e não conceito firmado e generalizado.

\section{PRODUÇÃO DE TRABALHOS DE ENFERMEIROS SOBRE O ASSUNTO}

Revisão bibliográfica do assunto permitiu conhecer alguns trabalhos de enfermeiros e os enfoques foram: HORTA ${ }^{12}$ abordou a assistência de enfermagem ao idoso baseado em suas necessidades básicas alteradas, acrescentando os aspectos de prevenção primária, secundária e terciária da assistência; FERNANDEZ 10 tece considerações sobre a situação do problema no Brasil, evidenciando os princípios básicos de geriatria, mostrando a prática geriátrica dentro da enfermagem, lembrando que a terapêutica religiosa (sem o sentido de direção e proselitismo) é também fundamental; BASTIAN ${ }^{2}$ fez um levantamento do número e das categorias da enfermagem que trabalham em internatos prestando assistência a pessoas idosas em relação com o número de leitos nestas instituições; MAGELA DE REZENDE 15 estudou o paciente geriátrico frente à cirurgia e às complicações pós operatórias, as causas dos deficits renais, os distúrbios emocionais e os deficits respiratórios do paciente geriátrico.

Relatos de experiências também foram publicados como o de GUIMARÃES ${ }^{11}$, que apresenta um estudo de caso e CAMPEDELLI ${ }^{8}$ que descreve uma experiência mais ampla vivida pela enfermagem de saúde pública do Centro de Saúde Experimental da Barra Funda, São Paulo, o "Grupo da Saudade" que funcionou objetivando a reintegração familiar e social do idoso.

BASTIAN $^{3}$ define o campo da enfermagem geriátrica e gerontológica, apresenta algumas teorias do envelhecimento e sugere temas para pesquisa na especialidade.

Estas informações foram valiosas porque mostraram alguns enfoques do problema. No entanto, como o que buscávamos saber é quais são os fatores, problemas e as determinantes que influem em suas vidas, identificando assim as necessidades geradas nas pessoas que chamamos de velhos, é que nos propusemos a elaborar este estudo.

\section{OBJETIVO}

Visando conhecer o que acontece às pessoas quando se tornam velhas, e quais as relações existentes entre a idade avançada com a própria pessoa, o trabalho, a família e a saúde, foram feitas entrevistas com pessoas idosas albergadas em instituições e as residentes na comunidade, obtendo-se informações que permitiriam posteriormente:

- fazer uma análise dos dados obtidos nos dois grupos comparando-os e identificando as semelhanças, contrastes e constantes;

- discutir e concluir baseado nesses resultados, as relações da velhice com a própria pessoa, o trabalho, a família e saúde;

- fazer propostas visando contribuir para a discussão do problema.

Espera-se que, ao final, os resultados obtidos possam contribuir para que o enfermeiro conheça alguns fatores que influem sobre a vida dos que envelhecem, para poder identificar os que realmente são da área da saúde e aí atuar em todos os seus níveis, proporcionando aos idosos uma velhice amparada e digna.

\section{METODOLOGIA}

Este estudo foi realizado através de uma entrevista, na qual se aplicava um questionário, anexo 1, em pessoas idosas residentes na comunidade ou em instituições filantrópicas. Para isso entramos em contacto com os dirigentes das instituições da cidade, pedindo permissão para que entrevistásse- 
mos os seus albergados e na comunidade falamos com algumas famílias e firmas para que permitissem nosso contacto com as pessoas a serem entrevistadas. Foi-nos dada autorização em todos os casos.

A escolha da técnica de coleta de dados através de um questionário, deveu-se ao fato da mesma permitir alcançar com menor custo e tempo, um grande número de pessoas.

O material foi pré-testado por onze (11) alunos de Habilitação de enfermagem em saúde pública e uma (1) enfermeira professora da disciplina de enfermagem de saúde pública da Escola de Enfermagem local, sendo essas mesmas pessoas as entrevistadoras.

Foi marcado um tempo para aplicação dos testes, ficando estipulado quatro (4) dias para as instituiçōes e oito (8) para a comunidade, sem nos preocuparmos com o estabelecimento do número de questionários a serem obtidos.

Foram entrevistadas as pessoas que tinham disponibilidade de tempo e condições para tal, pois algumas se achavam acamadas, indispostas ou em outra situação que impedisse ou dificultasse o diálogo.

4.1. População estudada

A população constou de pessoas residentes em Ribeirão Preto, com 60 ou mais anos no dia da entrevista e divididas em dois grupos:

a) albergados em instituições para idosos;

b) residentes na comunidade.

As instituições escolhidas foram: Solar Matusalém, Asilo Padre Euclides, Casa do Vovô (Sociação Espírita 5 de Setembro). Todas dentro do perímetro urbano da cidade.

São todas de caráter filantrópico, sendo as duas primeiras de orientação católica e a última espírita. Em nenhuma, no entanto, há obrigatoriedade de culto e pressão para proselitismo.

Há diferenças entre planta física, localização geográfica, disponibilidades de recursos, e forma de apresentação de seus programas assistenciais ao idoso, mas neste trabalho a instituição só foi considerada quanto a sua finalidade principal, albergar idosos, uma vez que estávamos voltados para a pessoa do velho e não para o seu grau de relacionamento e satisfação quanto a própria instituição. 


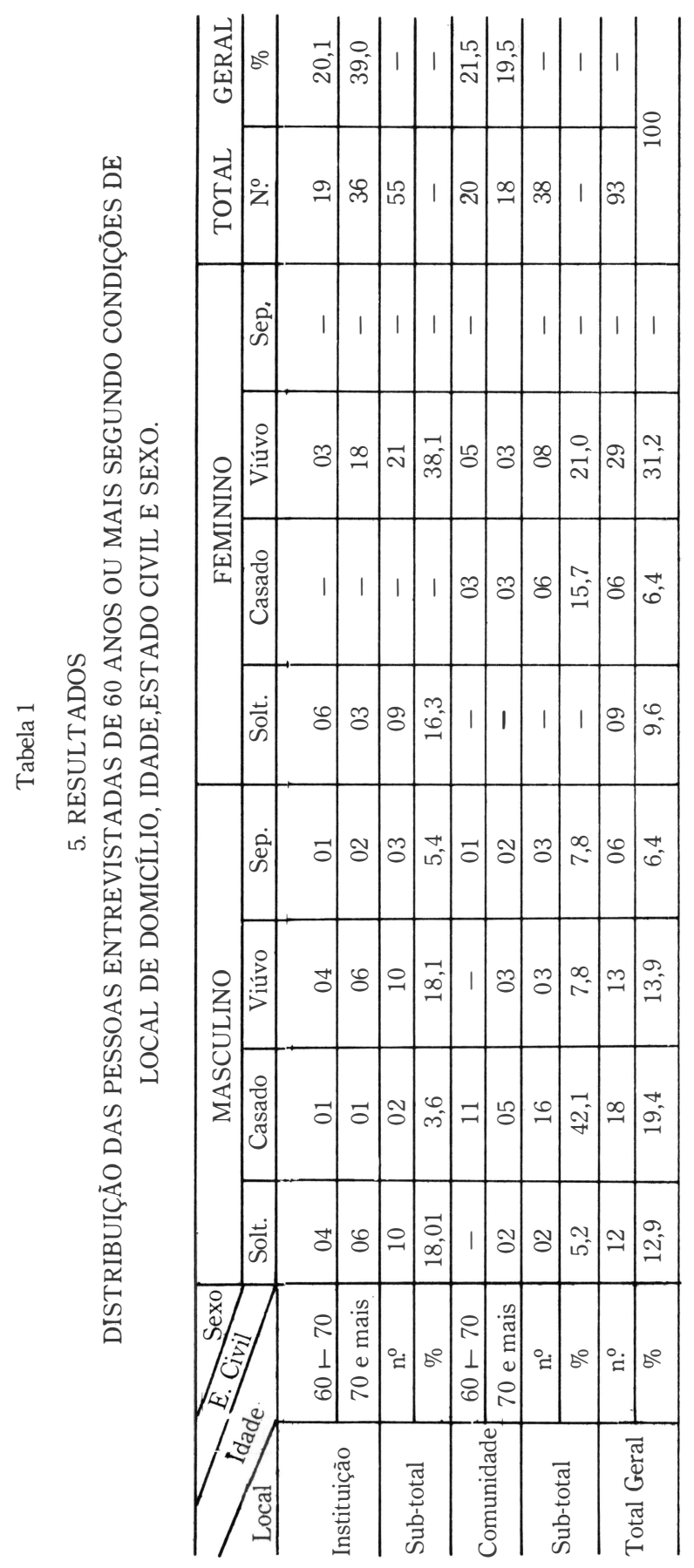


Gomes D.L.S. e Colaboradora - Os Idosos e a realidade da Velhice ${ }^{*}$ Rev. Bras. Enf.; RS, 36: $129-151,1983$.

Tabela 2

PESSOAS DE 60 ANOS OU MAIS POR CONDIÇÃO DE ATIVIDADE E SEXO SEGUNDO OS GRUPOS DE IDADE, DO ESTADO DE SÃO PAULO - 1980

\begin{tabular}{|c|c|c|c|c|c|c|}
\hline \multirow{3}{*}{ Gexo } & \multicolumn{6}{|c|}{ CONDIÇÃO DE ATIVIDADE } \\
\hline & \multicolumn{2}{|c|}{$\begin{array}{c}\text { Economicamente } \\
\text { Ativos }\end{array}$} & \multicolumn{2}{|c|}{$\begin{array}{c}\text { Não Economicamente } \\
\text { Ativos }\end{array}$} & \multicolumn{2}{|c|}{ TOTAL } \\
\hline & Homens & Mulheres & Homens & Mulheres & $\mathrm{n}$. & $\%$ \\
\hline 69 & 1.338 .190 & 260.476 & 956.633 & 2.203 .613 & 4.758 .912 & 61,8 \\
\hline 70 ou mais & 305.246 & 43.815 & 1.066 .978 & 1.524 .117 & 2.940 .156 & 38,1 \\
\hline TOTAL & 1.643 .436 & 304.291 & 2.023 .611 & $3.727,730$ & 7.699 .068 & \\
\hline$\%$ & 21,3 & 3,9 & 26,2 & 48,4 & & \\
\hline
\end{tabular}

FONTE: IBGE - 1981

Tablea 3

DISTRIBUIÇÃO DE PESSOAS ENTREVISTADAS DE 60 ANOS

OU MAIS, SEGUNDO CONDIÇÃO DE LOCAL DE DOMICÍLIO,

ATIVIDADE LABORAL, SEXO E APOSENTADORIA.

\begin{tabular}{|c|c|c|c|c|c|c|c|}
\hline \multicolumn{2}{|c|}{ APOSENTADORIA } & \multicolumn{2}{|c|}{ APOSENTADO } & \multicolumn{2}{|c|}{ NÃO APOSENTADO } & \multicolumn{2}{|c|}{ TOTAL } \\
\hline \multicolumn{8}{|l|}{ LOCAL } \\
\hline \multirow{2}{*}{ INSTITUIÇÃO } & ATIVO & 03 & 06 & 04 & 01 & 14 & 15,1 \\
\hline & INATIVO & 14 & 14 & 04 & 09 & 41 & 44,1 \\
\hline \multicolumn{2}{|l|}{ TOTAL PARCIAL } & 17 & 20 & 08 & 10 & 55 & 59,2 \\
\hline \multirow{2}{*}{ COMUNIDADE } & ATIVO & 09 & 01 & 02 & 10 & 22 & 23,6 \\
\hline & INAATIVO & 13 & 02 & - & 01 & 16 & 17,2 \\
\hline \multicolumn{2}{|c|}{ TOTAL PARCIAL } & 22 & 03 & 02 & 11 & 38 & 40,8 \\
\hline \multirow[b]{2}{*}{ TOTAL GERAL } & $\mathrm{N} !$ & 39 & 23 & 10 & 21 & 93 & \\
\hline & $\%$ & 41,9 & 24,7 & 10,7 & 22,5 & & \\
\hline
\end{tabular}



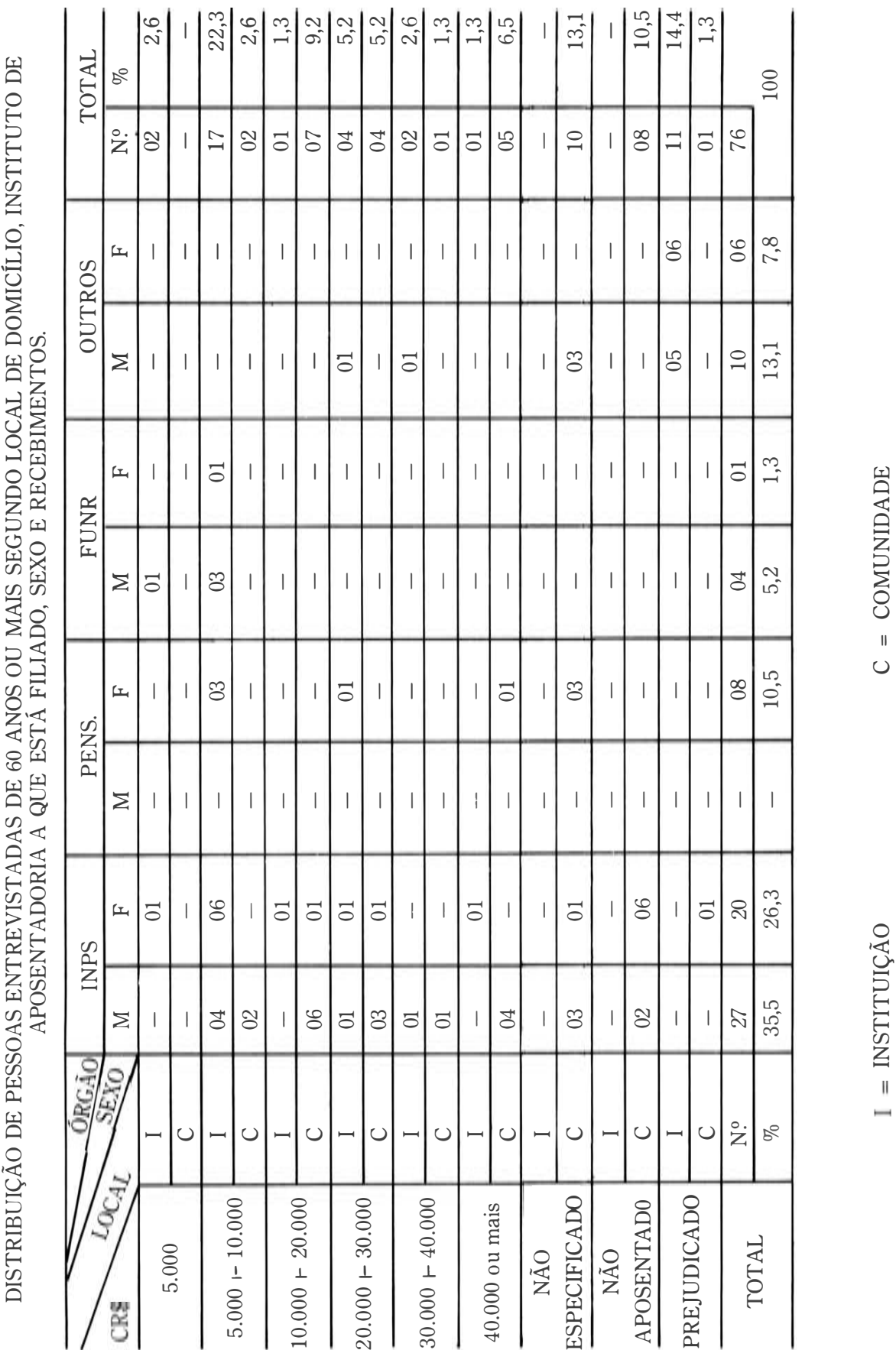
Gomes D.L.S. e Colaboradora - Os Idosos e a realidade da Velhice ${ }^{*}$ Rev. Bras. Enf.; RS, 36: $129-151,1983$

Tabela 5

DISTRIBUIÇÃO DE PESSOAS ENTREVISTADAS DE 60 OU MAIS ANOS SEGUNDO LOCAL DE DOMICÍLIO, SEXO E ATIVIDADE LABORAL ANTERIOR.

\begin{tabular}{|c|c|c|c|c|c|c|}
\hline \multirow[b]{2}{*}{$\begin{array}{l}\text { LABORAL } \\
\text { ANTERIOR }\end{array}$} & \multicolumn{2}{|c|}{ INSTITUIÇÃO } & \multicolumn{2}{|c|}{ COMUNIDADE } & \multicolumn{2}{|c|}{ TOTAL } \\
\hline & MASC. & FEM. & MASC. & FEM. & N. & $\%$ \\
\hline MASCATE & - & 01 & - & - & 01 & 1,0 \\
\hline MÉDICO & - & - & 01 & - & 01 & 1,0 \\
\hline METALÚRGICO & - & - & 01 & - & 01 & 1,0 \\
\hline ELETRECISTA & 01 & - & - & - & 01 & 1,0 \\
\hline INSP. FEDERAL & - & - & 01 & - & 01 & 1,0 \\
\hline MOTORISTA & - & - & 01 & - & 01 & 1,0 \\
\hline $\begin{array}{l}\text { ATENDENTE } \\
\text { ENFERMAGEM }\end{array}$ & - & 01 & - & - & 01 & 1,0 \\
\hline TÉCNICO CONTAB. & - & - & 02 & - & 02 & 2,1 \\
\hline OPERÁRIO & 01 & - & 01 & - & 02 & 2,1 \\
\hline FERROVIÁRIO & 02 & - & - & 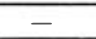 & 02 & 2,1 \\
\hline PROFESSOR & - & 01 & 01 & - & 02 & 2,1 \\
\hline PEDREIRO & - & - & 03 & - & 03 & 3,2 \\
\hline PREJUDICADO & 01 & - & - & 03 & 04 & 4,3 \\
\hline $\begin{array}{l}\text { MARCENEIRO/ } \\
\text { CARPINTEIRO }\end{array}$ & 02 & - & 03 & - & 05 & 5,3 \\
\hline $\begin{array}{l}\text { FUNCIONÁRIO } \\
\text { PÚBLICO }\end{array}$ & 01 & 01 & 02 & 01 & 05 & 5,3 \\
\hline COMERCIANTE* ${ }^{*}$ & 01 & 02 & 03 & - & 06 & 6,4 \\
\hline OUTRAS OCUPAÇŌES* & 01 & 07 & 05 & 02 & 15 & 16,1 \\
\hline LAVRADOR & 15 & 02 & - & - & 17 & 18,2 \\
\hline $\begin{array}{l}\text { DOMESTTICA/ } \\
\text { PRENDAS DOM. }\end{array}$ & - & 18 & - & 08 & 26 & 27,0 \\
\hline 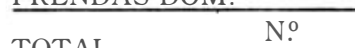 & 25 & 33 & 24 & 14 & 96 & \\
\hline$\%$ & 26,8 & 34,3 & 25,8 & 15,0 & & \\
\hline
\end{tabular}


Gomes D.L.S. e Colaboradora - Os Idosos e a realidade da Velhice ${ }^{*}$ Rev. Bras. Enf.; RS, 36: $129-151,1983$.

Tabela 6

DISTRIBUIÇÃO DAS PESSOAS ENTREVISTADAS COM 60 OU MAIS ANOS SEGUNDO LOCAL DE DOMICÍLIO, SEXO, EXISTÊNCIA DE FAMILIARES

E SEUS RESPECTIVOS LOCAIS DE RESIDÊNCIA.

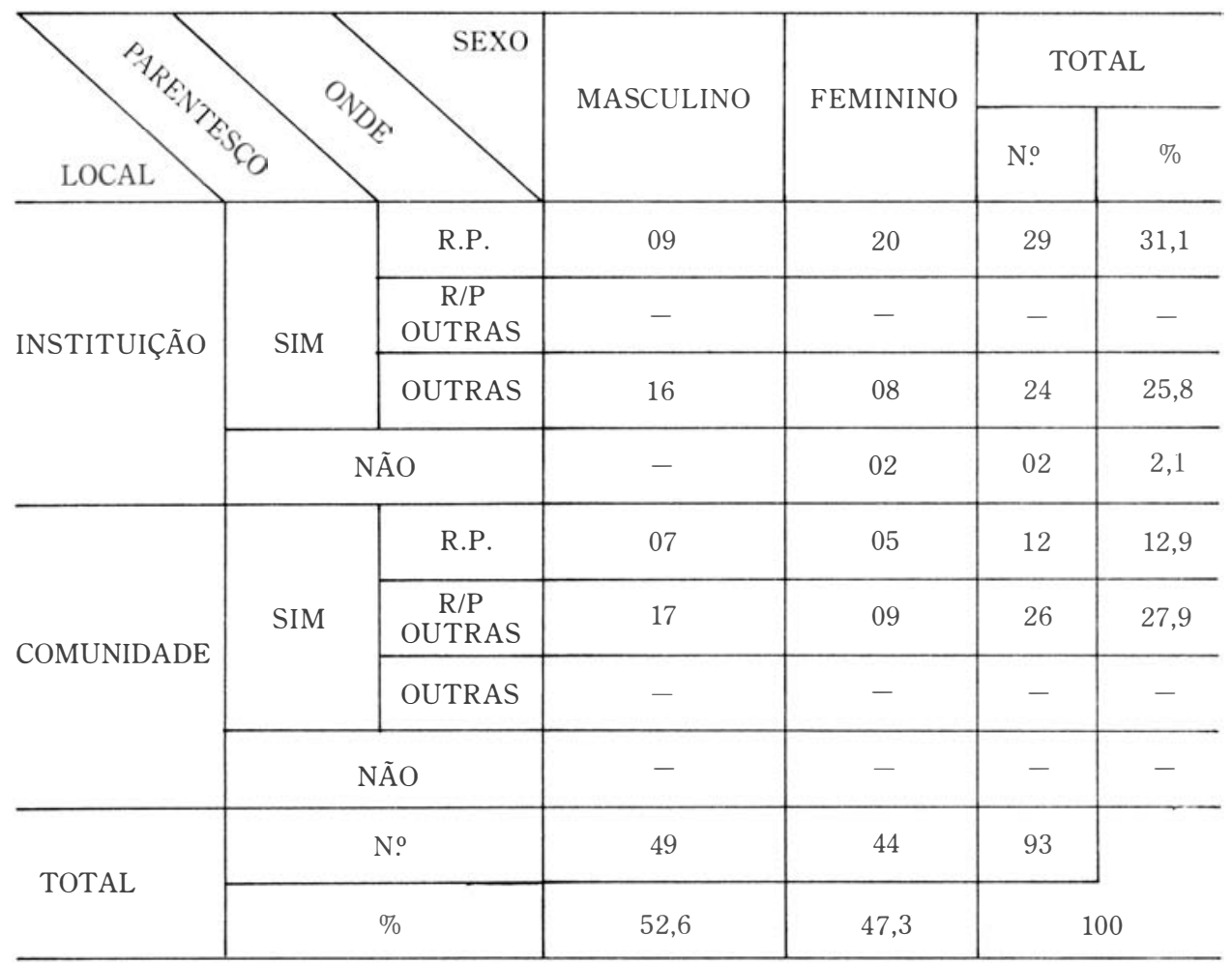




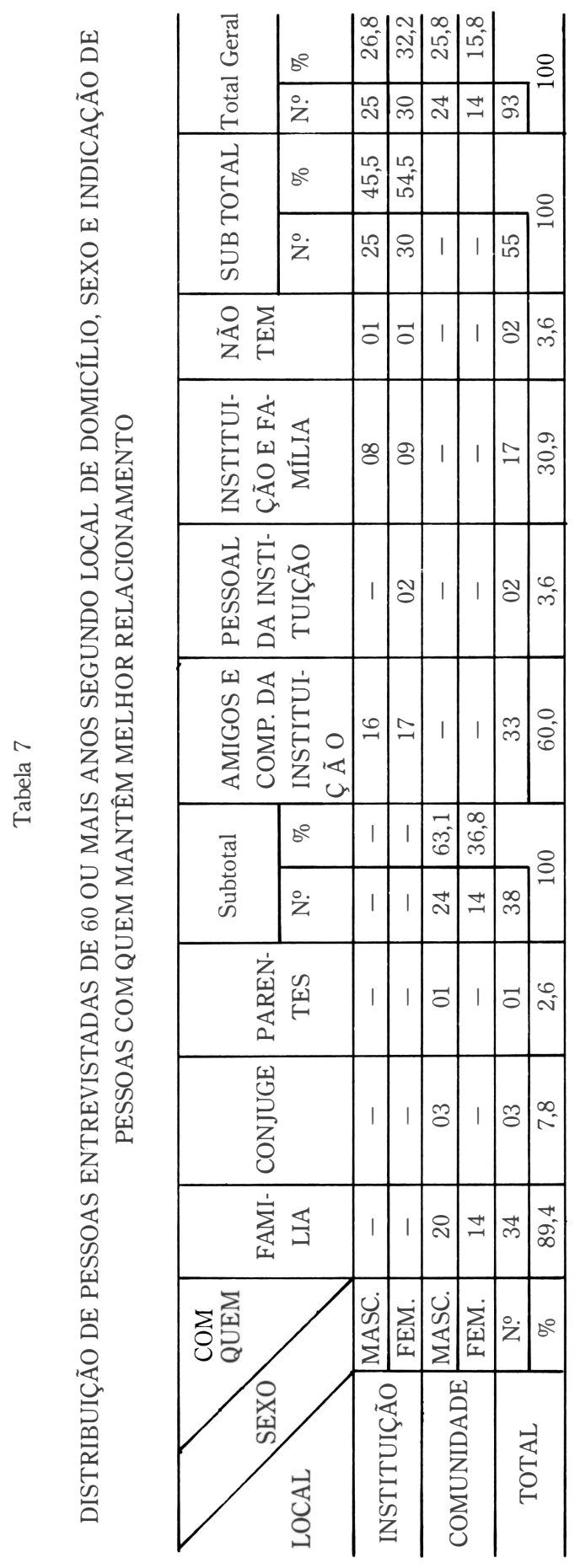


Gomes D.L.S. e Colaboradora - Os Idosos e a realidade da Velhice ${ }^{*}$ Rev. Bras. Enf.; RS, 36: $129-151,1983$.

Tabela 8

DISTRIBUIÇÃO DE PESSOAS ENTREVISTADAS COM 60 OU MAIS ANOS SEGUNDO CONDIÇÃO DE LOCAL DE DOMÍCILIO, SEXO E QUEIXA DE SAÚDE.

\begin{tabular}{|c|c|c|c|c|c|}
\hline \multirow{2}{*}{\multicolumn{2}{|c|}{ LOCAL }} & \multirow{2}{*}{ MASCULINO } & \multirow{2}{*}{ FEMININO } & \multicolumn{2}{|c|}{ TOTAL } \\
\hline & & & & N. & $\%$ \\
\hline \multirow{2}{*}{ INSTITUIÇÃO } & SIM & 13 & 19 & 32 & 34,4 \\
\hline & NÃO & 12 & 11 & 23 & 24,7 \\
\hline \multirow{2}{*}{ COMUNIDADE } & SIM & 05 & 05 & 10 & 10,7 \\
\hline & NÃO & 19 & 09 & 28 & 30,1 \\
\hline \multirow{2}{*}{ TOTAL } & N. & 49 & 44 & 93 & \\
\hline & $\%$ & 52,6 & 47,3 & \multicolumn{2}{|c|}{100} \\
\hline
\end{tabular}


Gomes D.L.S. e Colaboradora - Os Idosos e a realidade da Velhice * Rev. Bras. Enf.; RS, 36: $129-151,1983$.

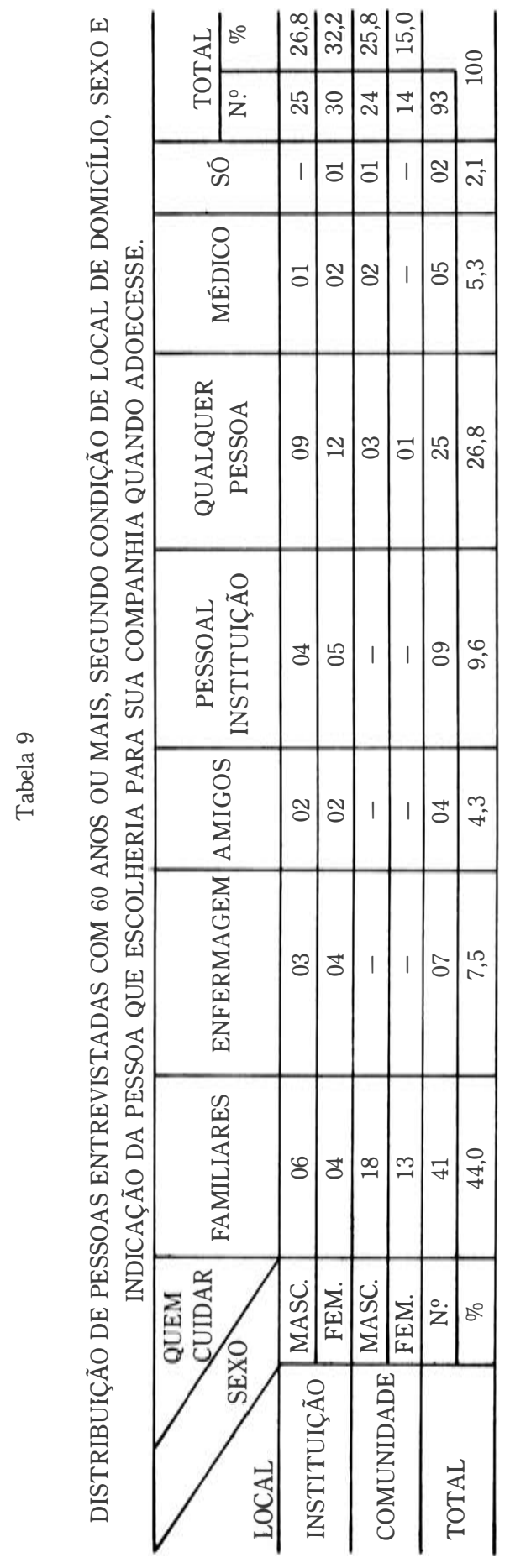




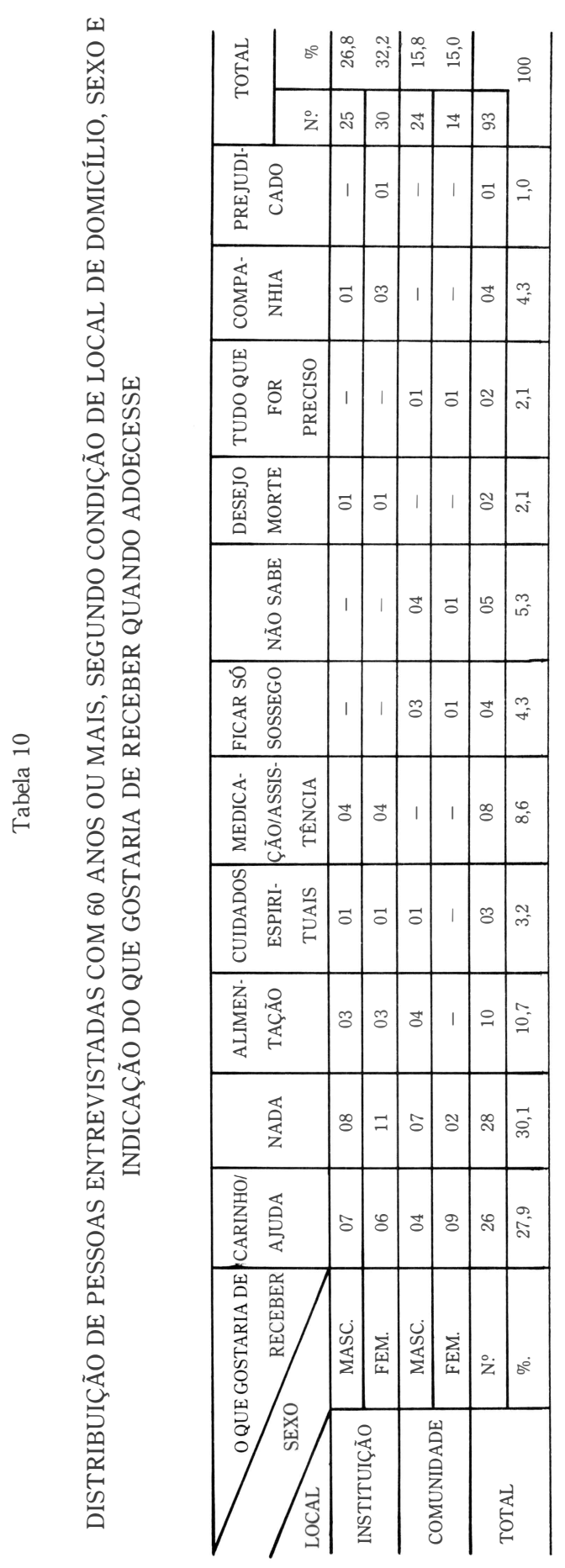




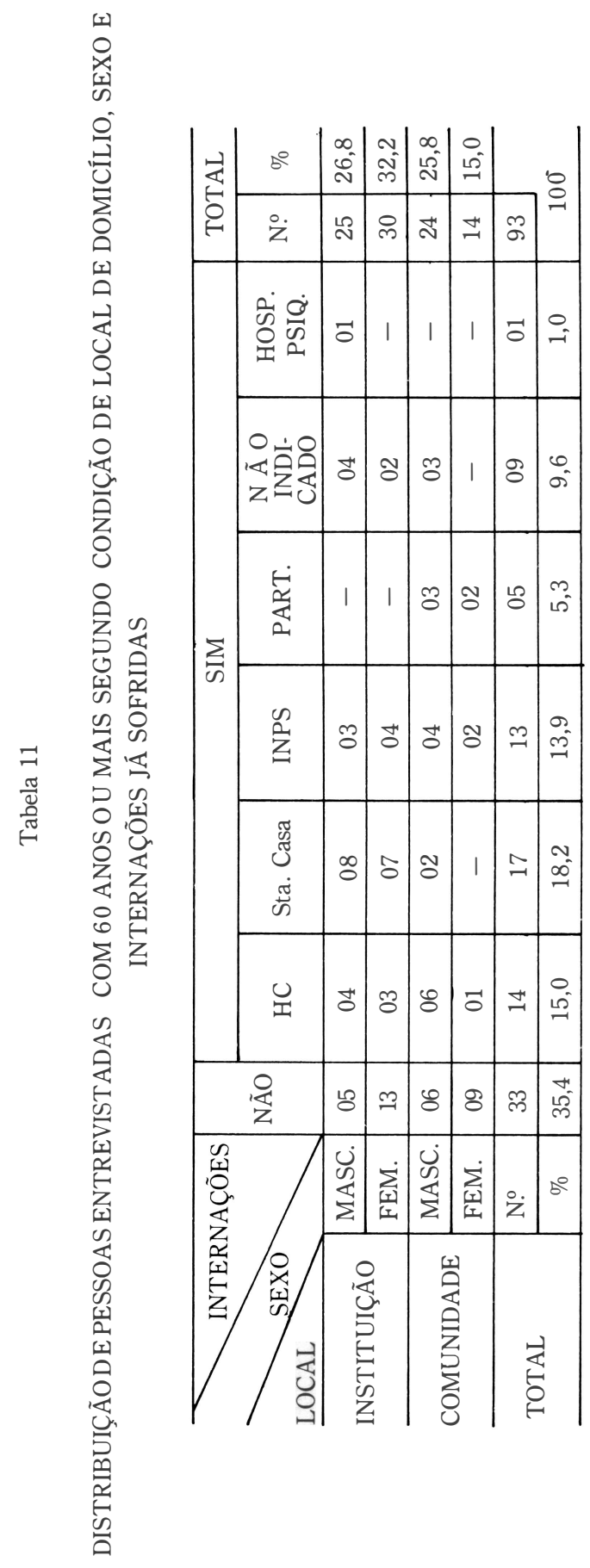




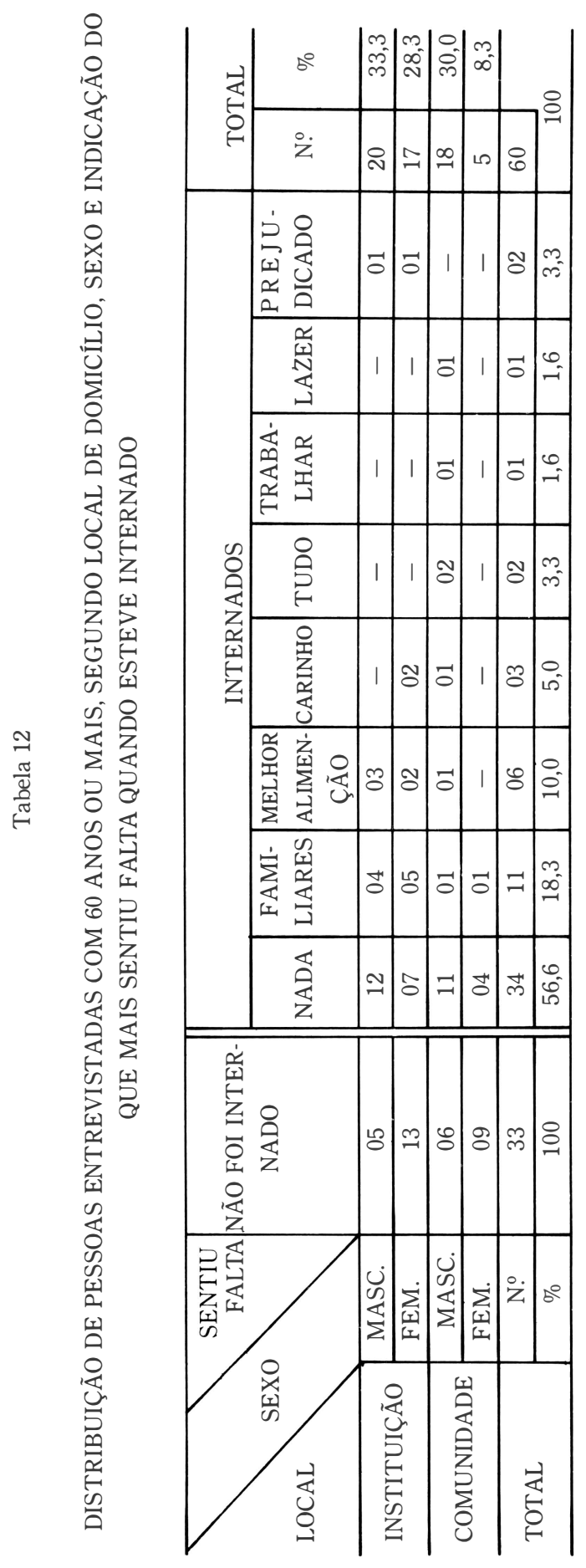


Gomes D.L.S. e Colaboradora - Os Idosos e a realidade da Velhice ${ }^{*}$ Rev. Bras. Enf.; RS, 36: $129-151,1983$.

\section{DISCUSSÃO}

\subsection{População Estudada}

Foram entrevistadas um total de 93 pessoas e dessas, 55 residiam em instituições para idosos e 38 residiam na comunidade com seus parentes e familiares.

A distribuição ficou, como mostra a tabela 1, dividida entre residentes em instituições e comunidade.

Das instituições, a maior parte dos entrevistados, entre os 55 , eram mulheres $54,5 \%$ (30); quanto ao estado civil, os viúvos 56,3\% (31); quanto à idade o grupo de 70 e mais anos com $39,0 \%(36)$.

$\mathrm{Na}$ comunidade, entre os 38 entrevistados, as maiores freqüências foram quanto ao sexo, os homens $63,1 \%$ (24); quando ao estado civil, os casados $57,8 \%$ (22) e quanto à idade, o grupo de 60 e 70 anos com $52,6 \%$ (20).

Vemos uma inversão dos resultados das variáveis consideradas entre comunidade e instituição.

O que pode explicar o fato é que, quando chegávamos às instituições, as mulheres se mostravam mais acessiveis e com mais disposição em nos atender, enquanto na comunidade, os homens é que se encontravam mais disponíveis, nas praças, nas ruas e bares. As mulheres entrevistadas na comunidade, foram aquelas a cuja porta batemos e solicitamos a entrevista nas casas.

Quanto ao estado civil, os idosos viúvos procuram mais as instituições por não terem recursos financeiros e dependerem de pessoas para manter-se, enquanto os que estão na comunidade são aqueles que têm ainda o cônjuge, o lar ou família.

A idade é explicada pelo mesmo fator: os mais velhos, mais dependentes e mais necessitados, vão para abrigos, enquanto os mais novos, permanecem com elas (as famílias).

Quanto ao número dos entrevistados ser maior na instituição, apesar do tempo menor, deve-se a disponibilidade dos mesmos num local geograficamente limitado e a vontade que eles demonstraram com as pessoas que os visitaram.

6.2. Trabalho - Tabelas $2,3,4$, e 5

A tabela 2 - mostra a condição de atividade das pessoas de 60 ou mais anos para o Estado de São Paulo. Os dados revelam que dessa população total (7.699.068) temos na inatividade $74,7 \%$ (5.751.341) ficando ativos apenas 25,30\% (1.947.727). Estes dados foram incluídos como referência para o atual trabalho, mostrando que essa inatividade se repetiu também em nossa comunidade.

Na tabela 3 - destacamos alguns dados, que nos pareceram de relevância. Do total $100 \%$ (93) dos entrevistados, 66,6\% (62) são aposentados e entre estes 30,6\% (19) estão realizando algum tipo de atividade, enquanto $69,3 \%$ (43) estão inativos, não realizando nenhuma atividade. Do total da população estudada, $100 \%$ (93) apenas 33,2\% (31) continuam fora da aposentadoria, o que não significa que estejam economicamente ativos, muitos não a conseguiram porque vieram da lavoura, ou nunca recolheram a institutos, e portanto não conseguem aposentar-se. A maior parte dos inativos está nas instituições, enquanto a maior freqüência de ativos é da comunidade.

Dos que estão aposentados recebendo algum tipo de remuneração, tabela 4, a maior parte dos entrevistados $22,3 \%$ (17) recebem entre 5 (cinco) a $\operatorname{Cr} \$ 10.000,00$, e são os albergados nas instituiçōes, enquanto que a maior freqüência dos residentes na comunidade tem salários de 10 (dez) a $\operatorname{Cr} \$ 20.000,00$, o que corresponde a 9,2\% (7). Encontramos um ponto de freqüência igual para a faixa de 20 a $\mathrm{Cr} \$ 30.000,00 \mathrm{com} 5,2 \%$ (4) para instituição e comunidade. A maioria dos aposentados está recebendo abaixo do valor do salário mínimo atual.

Segundo situação laboral atual e anterior na tabela 5, vemos a diversidade de profissões e ocupações, chamando a atenção para o fato de que as maiores freqüências foram, primeiro para doméstica e prendas domésticas $27,0 \%$ (26) e lavradores $18,2 \%$ (17), variando os demais em qualidade, com freqüências mais baixas, embora algumas tenham sido agrupadas.

Existe em nosso meio quase uma "crença" segundo a qual as pessoas idosas não podem trabalhar, especialmente quando alcançam a idade cronológica dos 70 , ou já completou um limite de anos de trabalho para a aposentadoria. Embora haja uma variação quanto a países, e segundo o sexo também, a parada compulsória parece levar a condição social do enve. 
lhecimento para muitas pessoas, isto talvez porque há em nosso país uma preocupação da produtividade econômica ligada ao valor pessoal. As pessoas mais idosas perdem o direito de continuarem ativas no trabalho, e passa a ser consideradas como pessoas incapazes de desempenharem trabalhos produtivos.

A capacidade de trabalho do velho é bem descrita na Saúde do Mundo16. "A capacidade de dominar novas especialidades diminue na velhice, muito embora o indivíduo tenha maior experiência e tenha acumulado mais conhecimentos. É difícil para o idoso adaptar-se a um novo emprego, e do ponto de vista social e econômico é melhor empregar pessoas capacitadas, de idade avançada que já tenham domínio na mesma indústria, na mesma oficina e departamento".

No entanto, como o sistema busca o lucro e o aumento da produtividade, os que atingem certa idade já não são capazes de se ajustarem ao ritmo da vida moderna e caem no desemprego e conseqüentemente nas demais dificuldades daí originadas.

HARRIOGTON apud BEAUVOIR4 "mostra que os velhos que vivem na indigência, o que já conhecemos, vivem em tugúrios miseráveis e insalubres, alimentam-se mal, não têm recursos para se tratar, e as suas doenças se agravam. Impedidos assim de trabalhar, exaspera-se-lhes a pobreza; envergonhados de sưa miséria, fecham-se em casa e evitam qualquer contato social. Não querem que os vizinhos saibam que vivem de assistência; privam-se dos pequenos favores e de um mínimo de cuidados que êstes lhes poderiam dar, e acabam ficando impossibilitados de deixar o leito".

Torna-se um ciclo; saúde precária, indigência e solidão. Tornam-se recrutas da miséria depois de uma existência de lutas, trabalhos e recursos oferecidos a seus familiares.

Perde-se com isso mão de obra já especializada que ao invés de estar inativa, poderia estar produzindo, invertendo-se os dados levantados, pois $66 \%$ dos estudados eram aposentados, e $69,3 \%$ desses são inativos.

A aposentadoria é determinada pelo Estado por idade ou por tempo de serviço no Brasil, tanto nos serviços públicos como privados. Nesse momento em que ele passa de ativo para inativo, dever-se-ia considerar o interesse de ambos, da sociedade e do futuro pensionista. Há por vezes o interesse exclusivamente da economia, eliminar rapidamente os que deixaram de auferir lucros, isto no sentido amplo, ou mesmo a disputa do lugar daquele que sai. Os mais jovens passam a disputar e desejar o lugar do mais velho, atitude que tem levado muitos idosos à miséria física e moral.

A solução mais correta seria permitir que continuassem ativos, enquanto pudessem, garantindo-lhes um nível satisfatório de vida e não essa situação gerada de se supor que velhice significa invalidez e aposentadoria, um auxílio que se concede a necessitados.

À medida que se aproxima a aposentadoria, alguns já começam a sentir-se como “desempregados".

A aposentadoria tem trazido ao idoso uma insatisfação muito grande. Vemos diariamente sentados nas praças da cidade onde gastam suas horas vazias, os "beneficiados pelo INPS" e com isso um acentuado declínio em sua vitalidade, a insatisfação, o envelhecimento prematuro, o isolamento da pessoa que perdeu suas posições, papéis, a ocupação socialmente útil, o grupo dos colegas e com isso a perda de seu vigor moral.

Foi feita em 1860 por SAINT-EUREMOND e anotada por BEAUVOIR 4 esta observação "O que se vê mais habitualmente entre a gente de idade é o anseio pela aposentadoria; e a coisa mais rara entre os que se afastaram é a ausência de arrependimento por o haverem feito".

Há uma observação a se fazer, dos efeitos diversos na mulher quanto a o ato de tornar-se mais velha e economicamente não ativa.

Considerando o número de mulheres jovens que não trabalham, a aposentadoria para elas não altera muito e a passagem de uma idade para outra não é tão acentuada.

O papel que a mulher desempenha no lar e na família, continua, daí não haver mudança na ocupação e na identidade.

A mulher prossegue com as responsabilidades do lar e o entretenimento das relaçōes afetivas com filhos e netos.

Pode surgir aí uma situação inversa da anterior, a mulher se torna superior ao homem, toma-lhe a frente e isto pode para algumas significar a desforra da humilhação sofrida anteriormente. Ela se torna a "chefe" da casa.

A aposentadoria, se traz oportunidades de descanso e lazer, traz para o homem uma 
ruptura com o passado e graves desvantagens: empobrecimento e desqualificação. Em geral as mulheres temem as conseqüências da aposentadoria do marido: baixa no padrão de vida, preocupações econômicas e mais, que ficará o dia inteiro atrás dela no lar. Podem estas situações levar o aposentado a hipocondria e desajuste no lar e no próprio casamento.

HEMINGWAY, citado por BEAUVOIR 4 diz "A pior morte para alguém é a perda daquilo que constitui o centro de sua vida e que faz dele aquilo que ele é na realidade. Aposentadoria é a palavra mais repugnante da língua. Que isto se faça por decisão própria ou porque o destino a tanto nos obriga; aposentarmo-nos e abandonarmos nossas ocupações - essas ocupações que fazem de nós o que somos - equivale a uma descida ao túmulo".

Além da grande perda de mão de obra, e os agravos à condição daquele que deixa de ter o seu trabalho e a sua ocupação, há o problema de ordem econômica, pois o salário diminui.

Quanto às pensões e pagamentos dos aposentados, o sistema dessa distribuição é notoriamente conhecido com o nome de "injustiça social". São chocantes as desigualdades; há casos excepcionais em que são satisfatórias, mas a maioria são vencimentos muito reduzidos.

Acho difícil a correção de nivelar os diferentes regimes ou pedir que os mais avantajados reduzam suas vantagens, no entanto os dados mostraram que dos entrevistados, a maioria recebe aposentadoria entre 5 e $\operatorname{Cr} \$ 10.000,00$ o que é insuficiente, uma vez que está muito abaixo do salário mínimo, que já é irrisório.

Foi constante entre os entrevistados albergados, o desejo de voltarem a trabalhar e a queixa por se sentirem pessoas inúteis, lembrando com saudosismo seus tempos de trabalho, os amigos, as tarefas e as realizações, enquanto que dos residentes na comunidade poucos referiram-se ao trabalho, uma vez que usam suas horas vagas em lazer e visitas a amigos e familiares.

Essa atitude generalizada de "aposentadoria", leva o idoso a marginalizar-se, e quando os efeitos aparecem, o problema é tratado como se fosse de natureza médica, isto é, como doença, mas ele precisa ser tratado na causa que é antes social - sua causa real, e não nos efeitos, agravos à saúde física e mental.

$\mathrm{O}$ velho enfrenta hoje o problema de nossa rápida industrialização, trocando o ambiente rural por uma vida em que os interesses sociais giram em torno de lucros. A tabela 4 assinalou a freqüência $18,2 \%$ (17) de lavradores, acostumados a uma vida familiar em que o velho continua a ter participação ativa e respeitada.

Como assinala KATHLEEN 13 , às pessoas à medida que envelheciam iam delegando suas funções de autoridade da fazenda, da casa, dos negócios para os membros mais jovens da família. Mantinham ainda o poder da casa não se tornando dependentes de seus filhos, dandolhes o sentimento de que ainda eram úteis e necessários.

Hoje encontramos esses antigos lavradores nas instituições que os albergam, sem condições de desfrutar de seu meio ambiente e familiar, onde durante anos deu toda sua força de trabalho, por uma remuneração tão irrisória que hoje, na sua velhice, o único lugar disponível e ao seu alcance é o albergamento em instituições, na condição de indigentes.

\subsection{Família - Tabelas 6 e 7}

A tabela 6, mostra que dos $100 \%$ (93) entrevistados, $97,8 \%$ (91) tem familiares, embora nem todos residam na cidade de Ribeirão Preto. Chama atenção, principalmente dos albergados, pois do total deles, $96,3 \%$ (53) tem familiares e destes $54,7 \%$ (29) residem na mesma cidade e $45,2 \%$ (24) residem em outras, enquanto que os que residem na comunidade, todos tem familiares.

Quando os entrevistados indicaram as pessoas com as quais melhor se relacionam, tabela 7, os resultados confirmaram a realidade. Para os albergados o melhor relacionamento $60,0 \%$ (33) é feito com amigos e companheiros da instituição, para os da comunidade com a família 89,4 (34). A família, para os albergados, foi indicada junto com os companheiros da instituição, aparecendo $32,7 \%$ (17) com essa indicação.

Como dissemos anteriormente, a urbanização das cidades e a mudança de uma sociedade de economia rural para industrial agudizou o problema das familias e elas sofreram duramente o processo.

Na zona rural, onde é mais freqüente a família reunida em várias gerações, existem certas vantagens, inclusive pelo apoio e auxílio dos pais aos jovens, mas por outro lado, quando o pai continua liderando ou é o dono dos negócios, surgem os conflitos das gerações mais no- 
vas com seus métodos e tecnologias avançadas, contra o pai que se irrita ante a modernização, coisa antes não ouvida e usada, entretanto os mais velhos continuam a serem os chefes.

Os filhos passam a aguardar às vezes com impaciência o afastamento dos velhos, ou partem os mais novos para as cidades em busca de outras frentes de trabalho. Às vezes é todo o grupo familiar que, premido pela condição, é obrigado a migrar para os centros urbanos, e as coisas se complicam de tal forma, que a família às vezes não pode ou não consegue manter o idoso no seio familiar e então o asilo constitui o único recurso dos velhos, quando já não são nem física e nem economicamente auto-suficientes.

Vários motivos levam os velhos a procurarem esse recurso: impossibilidade de continuar com os filhos; a dificuldade financeira de obter uma moradia e de mantê-la e às vezes rejeição dos mais novos.

O trauma do ingresso num asilo é um drama para o velho, principalmente para as mulheres que são mais apegadas ao lar e às crianças. Manifestam sinais de ansiedade e tensão.

Para alguns, às vezes, parece devolver um pouco da alegria, sentem-se menos isolados, têm amizades, são bem cuidados, recebem sua alimentação, têm seus objetos, sua cama e a supervisão da saúde. Não ficarão mais abandonados nas ruas ou nas casas de onde vieram.

Diz a Saúde do Mundo16, as pessoas idosas são quase sempre mencionadas como "problemas"; raramente em termos de solidariedade familiar e social ou das contribuições positivas que podem oferecer a outras gerações, particularmente quando lhes é permitido funcionar no ambiente de seu próprio lar.

Pelo fato de pouco ou nenhuma contribuição darem ao produto nacional bruto de um país, os velhos passaram a ser "geração indesejada".

A forma ou maneira pela qual o velho é excluído do grupo familiar, se faz à s vezes de forma sutil e enganosa. É uma manobra, alegam estar agindo para o interesse de um bem estar para ele, e às vezes com a anuência de toda a família, recorre-se a mentiras para convencê-lo a entrar provisoriamente para um asilo e aí o abandonam. Torna-se nesta hora o objeto incômodo e inútil, desprezível, improdutivo e muitas vezes mais uma boca a ser alimentada.

Outras vezes o tratamento é inverso, continua na família, mas com tratamentos irônicos, zombeteiros, recebendo “indiretas", e outros tratamentos adversos que o desgasta e o destrói intimamente. Perdem o direito de mandar e pedir dentro de suas próprias casas. Tornam-se acintosamente tratados como intrusos na casa que lhes pertence e pela família que manteve e sustentou.

\subsection{Saúde - Tabelas $8,9,10,11$ e 12}

A tabela 8 mostra as queixas de saúde dos entrevistados. Os $100 \%$ entrevistados, $45,1 \%$ (42) apresentam queixas, enquanto $54,8 \%$ (51) não registrou nenhuma queixa. As mulheres se mostraram mais queixosas $25,8 \%$ (24) contra $19,3 \%$ (18) homens.

A indicação de pessoa para lhes fazer companhia na doença, tabela 9 , foi em primeiro lugar a família $44,0 \%$ (41), sendo os da comunidade os de maior freqüência; em seguida qualquer pessoa 26,8\% (25) e pessoal da instituição em terceiro lugar 9,6\% (09). É interessante notar que o pessoal albergado em instituições mencionou enfermagem $7,5 \%$ (07), talvez porque as instituições são visitadas e algumas já tiveram alunos de enfermagem como estagiários. Outra alternativa, é o uso dos chamados "enfermeiros" (atendentes) que prestam assistência diuturna nas instituições.

A tabela 10 assinala a freqüência dos que gostariam de receber quando doentes. Em primeiro lugar: nada 30,1\% (28), em segundo, carinho e ajuda 27,9\% (26) e em terceiro alimentação 10,7\% (10). A condição "nada", parece estar relacionada ao sentimento expresso por alguém que sente estar recebendo já uma ajuda e não quer pedir mais uma, pois carinho e ajuda ficou numa freqüência bem próxima. A alimentação foi destacada. Alguns chegaram até a dar a receita de caldos e sopas que gostariam de receber.

Dos entrevistados $64,5 \%$ (60) segundo tabela 11, já haviam sofridoalgum tipo de internação, em diferentes hospitais, enquanto 35,5\% (33) não sofreu nenhum tipo de internação.

Perguntados sobre o de que mais sentiram falta quando estiveram internados, tabela 12 , a resposta de maior freqüência foi: nada $56,6 \%$ (34) seguida de familiares $18,3 \%$ (11) e em terceiro lugar alimentação 10,0\% (06). As variáveis "nada" e "alimentação" voltam a ser citadas. A preocupação com o alimento e a preocupação em não queixar-se de algo que lhe foi oferecido, persiste. 
Esses resultados relacionados à saúde como um todo, vêm clarear um pouco a confusão entre processo de envelhecimento e os processos patológicos.

Os números indicam que de um modo geral o idoso física e mentalmente tem condições de equilíbrio de saúde, mas vive freqüentemente entediado e em solidão, e que muitos têm problemas sociais e econômicos que são muito maiores e importantes que a sua saúde.

Há muita queixa, como uma "somatização" de um estado de solidão e inatividade física e intelectual em que se encontram, ficando às vezes difícil dissociar o físico do psíquico.

Nossa experiência leva-nos a dizer que na mulher essas manifestações são mais freqüentes que no homem e portanto são estas que consomem mais medicamentos e procuram mais serviços médicos, e se mostram mais queixosas que os homens.

Há um preconceito bastante difundido de que os velhos dormem mal, no entanto nenhum deles referiu perturbação do sono, a não ser alguns que acordam muito cedo, ou o sono intercalado. É preciso observar que muitos deles dizem dormir depois do almoço ou fazem um repouco nas cadeiras ou sofás. Tiram seus cochilos, com isto diminuem as horas do sono noturno. Referiram levantar cedo, mas não insônia.

Para alguns o albergarem-se nas instituições é um acontecimento difícil de ser enfrentado, com isto sentem-se infelizes, tristes, voltando-se para dentro de si mesmos, com dificuldades em adaptarem-se e comunicarem-se com os outros. Este acontecimento pode acelerar alguns processos patológicos e até mesmo o envelhecimento, pela condição em que a pessoa se encontra.

Alguns velhos encaram sua situação como sendo de tal forma intolerável que preferem a morte ao "suplício de viver". O número de suicídio á ainda alto na velhice e DURKHEIN foi o primeiro a fazer levantamento estatístico demonstrando a crescente porcentagem de suícidios, dos 40 a 80 anos, com número maior de homens, como foi assinalado por BEAUVOIR ${ }^{4}$.

"A psicose raramente é a causa de suicídio dos velhos. Este seria explicado por fatores sociais e psicológicos: declínio físico e mental, solidão, ociosidade, inadaptação, doença incurável. O suicídio nunca resulta de um episódio depressivo singular, isolado, mas sim da história de toda a existência", é o que diz CRUHLE citado também por BEAUVOIR ${ }^{4}$.

O reverendo CHAD VARAH que é fundador do trabalho de prevenção ao suicídio, diz que pessoas mais velhas têm tendência em procurar a própria morte devido a fatores físicos e sociais em que se encontram, além da solidão e do desprezo dos quais muitos se sentem vítimas. Mostrou o exemplo da Hungria com $42 \%$ de casos de suicídio para cada 100 mil habitantes e entre estes a ocorrência maior entre os velhos, aqueles que conheceram uma outra situação do país e não se adaptam ao novo regime para o qual não participaram da transformação ${ }^{9}$.

O problema do idoso é de âmbito global e não pertence somente à area da saúde.

Podem-se sugerir medidas que venham contribuir para fortalecer a saúde física e espiritual do idoso, melhorando seu bem estar e assegurando à sociedade a possibilidade dos mais novos adquirirem com os mais velhos alguma parcela de seu cabedal de conhecimentos e de experiências.

Por outro lado, eles poderiam contribuir para a melhoria da situação econômica do país desde que se estabeleçam as condições de trabalho mais fáceis para as pessoas capacitadas ativas ou aposentadas de idade avançada, para que sejam beneficiadas com um trabalho de ritmo menos intenso ou apenas em tempo parcial. Este esforço poderia ter apoio dos sindicatos, dos serviços de saúde, de empresas e indústrias, da previdência social e dos interessados em geriatria e gerontologia.

Sabendo que os idosos apresentam dificuldades para superar períodos de aprendizagem, que o nervosismo e a ansiedade provocam perdas de memória, o que se acentua num caso em que ele vá competir com jovens, dever-se-ia procurar contrariar essas dificuldades oferecendo-lhes condições que permitam readaptá-los ao trabalho.

Tentando retardar o processo do envelhecimento e procurando assegurar a integridade física, mental e social, procurar beneficiá-los com um ambiente que seja socialmente ativo. bom, amigo, que é o meio famlliar, pois a tentativa de solucionar problemas sociais e de saúde através da construção de instituições, por melhores e mais bem montadas que sejam, será falho, pois elas não suprirão a vida ativa que o idoso teria junto a seu grupo familiar.

Deve-se mostrar que o melhor ambiente, onde o idoso possa viver sendo amado e respeitado, ao mesmo tempo que ele também ama e respeita, é o seu próprio lar, onde afeto e participação serão as bases de sua existência. 
Gomes D.L.S. e Colaboradora - Os Idosos e a realidade da Velhice ${ }^{*}$ Rev. Bras. Enf.; RS, 36: $129-151,1983$.

\section{CONCLUSÕES}

7.1. Da bibliografia consultada, não foi possível identificar uma definição do que é a velhice e quem é o velho. As proposições permearam desde conceituações que se basearam na idade cronológica, na aposentadoria, alteraçōes físicas, psicológicas, intelectuais até as que incluem o caráter subjetivo e pessoal.

7.2. Os trabalhos de enfermeiros, que foram consultados, sobre o assunto, não discutiram as ligações sociais implicadas no processo, enfocando mais a parte de assistência em seus vários níveis, inclusive relatos de experiência e teorias que sugerem temas para pesquisa.

7.3. O marco cronológico estabelecido para o trabalho - 60 anos, - foi arbitrário e de ordem metodológica, não se inferindo que o mesmo deva ser generalizado.

7.4. Do total de 93 pessoas entrevistadas, 38 residiam na comunidade, dessas a maioria eram homens $63,1 \%$, casados $57,8 \%$, pertencentes ao grupo etário de 60 a 70 anos, $52,6 \%$; enquanto que nas instituições a maioria eram mulheres $54,5 \%$, viúvos $56,3 \%$, na faixa etária de 70 anos e mais, $39,0 \%$.

7.5. Dos entrevistados $66,6 \%$ são já aposentados e destes $69,3 \%$ estão na inatividade. Entre os que recebem aposentadoria, a maior parte, $22,3 \%$ recebem abaixo do nível do salário mínimo, quanto a atividade anterior, $27,0 \%$ eram domésticas/prendas domésticas (sexo feminino) e $18,2 \%$ lavradores (sexo masculino).

7.6. A aposentadoria aparenta trazer conseqüências em perda de mão de obra já especializada, insatisfação pela inatividade, perda de posição, problemas de ordem econômica pela baixa renda, gerando resultados negativos que são tratados como se fossem de natureza médica. Esta situação foi mais acentuada nos albergados, onde estão muitos dos migrados da zona rural.

7.7. Entre os idosos entrevistados, $96,3 \%$ possuem famílias, no entanto entre eles, $59,1 \%$ (55) são albergados e entre esses $54,7 \%$ de suas famílias residem na mesma cidade. Mais uma vez a urbanização parece ser um dos fatores a gerar o banimento do idoso do meio familiar, causando efeitos deletérios pela separação e o isolamento, ao mesmo tempo a impossibilidade do idoso obter e manter uma moradia para si.

7.8. As queixas de saúde do grupo trabalhado foram de $45,1 \%$, sendo as mulheres mais queixosas que os homens, ( $25,8 \%$ mulheres e $19,3 \%$ de homens). A familia foi a mais indicada para fazer companhia durante a doença. A maior parte $30,1 \%$ nada tem a pedir quando doentes, mas $27,9 \%$ querem carinho e ajuda. Dentre os que já sofreram internações dizem em $56,6 \%$ que de nada sentiram falta, mas $18,3 \%$ sentiu falta dos familiares. Embora com freqüência menor a alimentação foi anotada tanto na doença como na internação.

7.9. Algumas sugestōes foram lembradas como reaproveitamento dos idosos para trabalhos ajustados à sua possibilidade, estudo de aposentadoria gradual, amparo de ordem social e econômica à população, programas para idosos, como forma de manter a sua integridade física, espiritual e social. Durante o trabalho deu para sentir que vivem melhor a velhice os que possuem renda suficiente, que continuam a exercer algum tipo de atividade e receberam algum tipo de educação.

7.10 No conjunto a situação dos idosos mostrou estar mais ligada ao campo social que à saúde, necessitando de coordenação de esforços (sociais, econômicos, saúde), para formulação de uma política que vise beneficiar os idosos.

7.11.O trabalho trouxe grande satisfação aos que o realizaram e aos idosos que participaram. Recebemos vários agradecimentos por parte deles, por termos ido procurá-los, ouvindo-os, e serem eles alvo de um trabalho. Por outro lado, os alunos estagiários participantes gostaram muito da experiência e mostraram-se gratificados pela oportunidade. Para os enfermeiros ele poderá trazer informações ou servir como um piloto ou referência para trabalhos futuros.

\section{SUMMARY}

The elderly and the realities of old age.

With the intention of discovering what happens to people as they grow old an what they themselves think about aging, the authors interviewed a total of 93 old people. Of these, 55 lived in homes for the elderly and 38 lived in the community. The results obtained demonstrate some of the relationships between old age and work, the family and health, showing that social factors influence aging and the life style of the aged. 
Gomes D.L.S. e Colaboradora - Os Idosos e a realidade da Velhice * Rev. Bras. Enf.; RS, 36: $129-151,1983$.

\section{BIBLIOGRAFIA}

1. AUMENTA no mundo o número de velhos. O Estado de São Paulo, São Paulo, 7 abr., 1982, p. 16.

2. BASTIAN, Ernestine M. Pessoal de enfermagem na assistência à saúde da pessoa idosa. Enferm. Novas dim., 3 (3): 131-135, 1977.

3. BASTIAN, Ernestine, M. Gerontologia: campo da enfermagem. Enferm. Novas dim., 5 (2): 17-22, 1979 .

4. BEAUVOIR, Simone de. A velhice - a realidade incômoda. Trad. Heloysa de Lima Dantas. 2a ed., São Paulo, Difusão Européia do Livro, 1976, V. 1.

5. BEAUVOIR, Simone de A velhice as relações com o mundo. Trad. Heloysa de Lima Dantas. São Paulo, Difusão Européia do Livro, 1970, V. 2.

6. BÍBLIA SAGRADA. Eclesıastes Trad. João Ferreira d'Almeida. Lisboa. Sociedade Bỉblica Britânica e Estrangeira, 1955 cap. 12

7. BRASIL - Instituto Brasileiro de Geografia e Estatística Censo Geral do Brasil de 1980. Resultados preliminares, 1981, Vol. 1 - t. 2.

8. CAMPEDELLI; Maria Coeli. Assistência de Enfermagem de Saúde Pública a um grupo de velhos. Relato de uma experiência. Enferm. novas dim., São Paulo, 4 (2): 86-89. 1978;

9. ESPECIALISTA explica índices de suícidio. Estado de São Paulo. São Paulo, 13 abr. 1982, p. 18. (6)9.

10. FERNANDES, Clea A. F. Enfermagem geriátrica. Rev. Bras. Enferm., Rio de Janeiro, 20 (1): 46-55, jan./fev., 1967.

11. GUIMARÃES, Raquel Maria M. Assistência a um paciente geriátrico - estudo de caso. Rev. Bras. Enferm., Brasília, 31 (4): 542-566, 1978.

12. HORTA, Wanda de A. A assistência de enfermagem ao adulto idoso. Enf. Novas dim., São Paulo, 4 (5): 268-273, 1978.

13. KATHLEEN, Newton R. N. Geriatric Nursing, 2nd edit. St. Louis The C. V. Mosby, 1954.

14. KERVOR, Stéphane. As universidades da "terceira idade". Paris. Embaixada da França, 1976 (France Informations, 73)

15. MAGELA de REZENDE, Ana Lúcia. O paciente geriátrico face à cirurgia. Rev. Bras. Enferm. Brasília, 28 (1): 38-47, 1976.

16. ORGANIZAÇÃO MUNDIAL DA SAÚDE. A Idade Avançada. Saúde do Mundo. Genebra, abril, 1979.

\section{ESCOLA DE ENFERMAGEM DE RIBEIRÃO PRETO INQUÉRITO COM PESSOAS IDOSAS}

Anexo 1

1. IDENTIDADE
a) idade: $60 \vdash 70$
70 e mais
b) sexo: masc. . .
fem

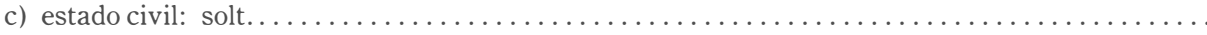
cas.

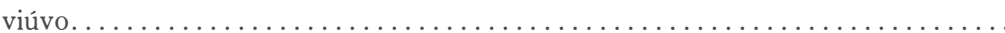

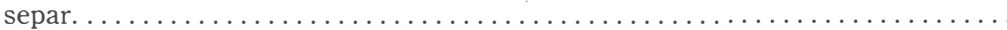
d)residência: casa

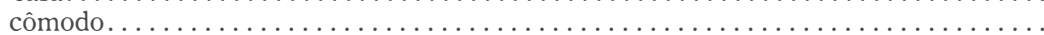

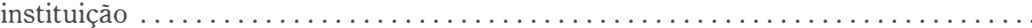

e) com quem mora:

f) outras informações:

2. TRABALHO

a) está trabalhando? sim, não

( $\operatorname{sim})$ o que faz?

b) está parado? por que? .

c) é aposentado por INPS ou outro órgão? (especificar) 
Gomes D.L.S. e Colaboradora - Os Idosos e a realidade da Velhice ${ }^{*}$ Rev. Bras. Enf.; RS, 36: $129-151,1983$.

d) quanto recebe de aposentadoria? (se quiser responder)

e)

f)

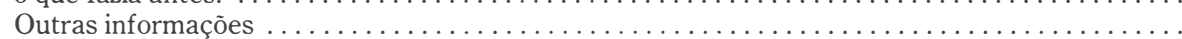

3. FAMÍLIA

\begin{tabular}{|c|c|c|c|c|}
\hline \multirow{2}{*}{ tipo parentesco } & \multirow{2}{*}{$\operatorname{sim}$} & \multirow{2}{*}{ não } & \multicolumn{2}{|c|}{ residência } \\
\hline & & & Ribeirão Preto & Outra cidade \\
\hline $\begin{array}{l}\text { pai } \\
\text { mãe } \\
\text { esposa } \\
\text { filhos } \\
\text { irmãos }\end{array}$ & & & & \\
\hline
\end{tabular}

a) com os quais tem mais contacto?

b) com quem se relaciona mais e melhor? (amigos, parentes, vizinhos, companheiros de trabalho, instituição, etc.)

outros

\section{SAÚDE}

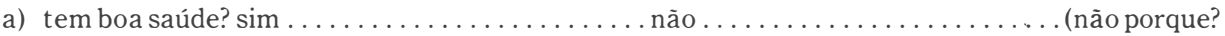

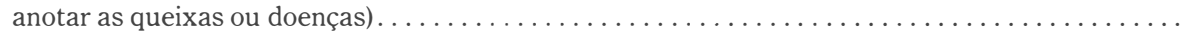

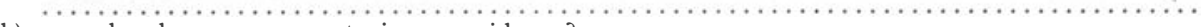

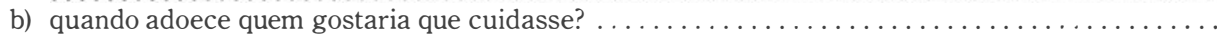

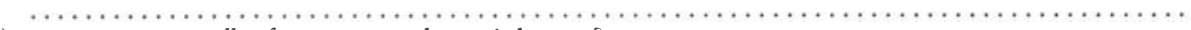

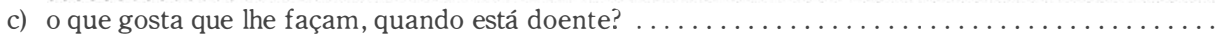

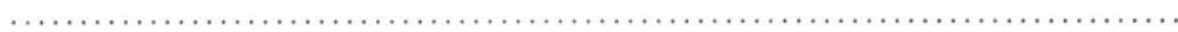

d) já esteve internado alguma vez? onde?

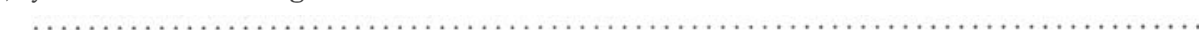

e) de que sentiu falta quando esteve no hospital? $\ldots \ldots \ldots \ldots \ldots \ldots \ldots \ldots \ldots \ldots \ldots \ldots \ldots \ldots$

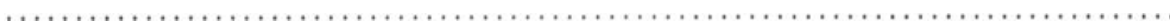

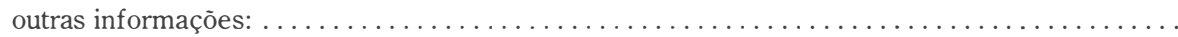

OBSERVAÇÕES DO ENTREVISTADOR (pode ser por pergunta)

a) anotar sobre a deambulação da pessoa (se anda bem, cadeira de rodas, bengala, só apoiada,

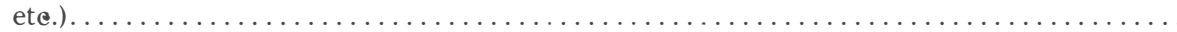

b) se a pessoa consegue se alimentar (sozinha e se faz bem) $\ldots \ldots \ldots \ldots \ldots \ldots \ldots \ldots \ldots \ldots \ldots$

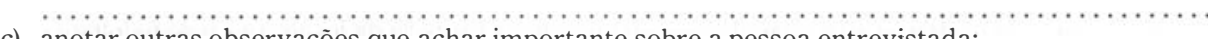

c) anotar outras observações que achar importante sobre a pessoa entrevistada: . . . . . . . . .

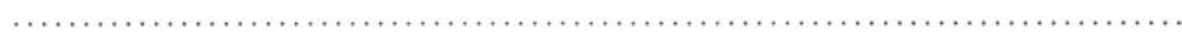

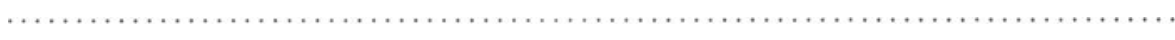


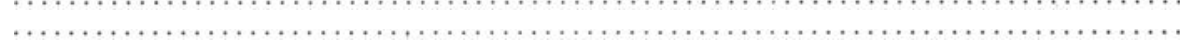

\section{DATA}

assinatura do entrevistador 